while walking to school. Teens did not perceive distraction putting them at greater risk. Findings were used to build "The Moment of Silence" Campaign, which uses social media to engage teens.

Conclusions Many teens and pre-teens are distracted while walking, but do not perceive this behaviour as risky. Targeted interventions are needed.

\section{MODEL SCHOOL ZONE PILOT PROJECT DEMONSTRATES RESULTS IN IMPROVING PEDESTRIAN SAFETY}

Priti Gautam, Kristin Rosenthal. Safe Kids Worldwide, USA

\subsection{6/injuryprev-2016-042156.906}

Background From 2011-2014, the Model School Zone pilot project was implemented in 10 countries to improve pedestrian safety around 10 schools. Through multi-country data analysis, we sought to demonstrate that the program was effective in improving pedestrian safety and adaptable in low-, middle- and high-income countries.

Methods The project was implemented in three phases over an 18-month period. During Phase I, grantees selected a school based on specific criteria and conducted a baseline needs assessment. The needs assessment included a school zone infrastructure assessment tool, student knowledge and behaviour surveys, participatory research tools and parent surveys. In Phase II, grantees implemented interventions based on the needs and risks identified. Interventions focused on permanent infrastructure changes but also included education and advocacy initiatives. In Phase III, grantees evaluated the effectiveness of the interventions.

Results Behavioural surveys with 1,606 children showed that most walk to and from school, most walk alone, and most do not feel safe near their schools. Parent surveys revealed that more than half felt uncomfortable about their child's safety on the way to school, with speed of cars the highest rated concern. Permanent modifications were made to environments around 10 schools in 10 countries, resulting in changed behaviour and reduced injury. In Vietnam, for example, the number of fatalities decreased three-fold. Results and lessons learned were used to develop the Safe School Zone project, launched in 2015.

Conclusion A phased approach to creating safe school zones focused on environmental changes, education and advocacy, is adaptable to low-, middle- and high- income countries, and leads to reduced fatalities and injuries.

\section{BUILDING SUSTAINABLE NATIONAL CHILD PASSENGER SAFETY TECHNICIAN TRAINING PROGRAMS}

Lorrie Walker, Mark Isaac, Kate Carr. Safe Kids Worldwide

\subsection{6/injuryprev-2016-042156.907}

Background Safe Kids Worldwide (SKW) is designated by the US government as the certifying body for car seat technicians in the US. Since 1998, more than 140,000 child passenger safety (CPS) technicians have been certified, and more than 38,000 technicians and 1300 instructors are currently active. This successful US model has made CPS part of the social norm in which child restraints are used until seat belts fit. However, many nations have yet to build a CPS system that is proven to save children's lives.

Methods SKW cooperated with partners to create culturally sensitive pilot training programs in China, Qatar, Mexico, Abu Dhabi, and Israel. Training programs relied on a step-by-step approach to achieve sustainability. Each nation identified stakeholders, provided awareness training, and encouraged participants to become technicians. Certification classes focused on training technicians and on identifying and training local instructors. By the third class, China and Qatar certified a pool of technicians and instructors qualified to train more local experts. Also, new instructors were mentored to become lead instructors who keep technicians engaged and work with stakeholders to create a coordinated national CPS strategy.

Results China trained 60 technicians and 3 instructors and is poised to expand its program. Qatar certified 70 technicians and 5 instructors while advancing a nationwide CPS program. All countries have ongoing classes.

Conclusions The model demonstrated methodical success in creating a sustainable pool of trained CPS technicians in China and Qatar to reduce child injuries and fatalities. This model shows great promise for spreading CPS expertise and creating a new safety norm around the world.

\section{PARENT ATTITUDES AND BEHAVIOURS ON ROAD TRAFFIC INJURIES AFFECTING CHILDREN}

Kate Carr, Rennie Ferguson, Manxi Yang, Lorrie Walker, Mark Isaac. Safe Kids Worldwide

\subsection{6/injuryprev-2016-042156.908}

Background With an epidemic of traffic injuries affecting children worldwide, a better understanding of the data, including parent attitudes and behaviours, is essential.

Methods A survey was conducted among a diverse group of 6000 parents in six nations in 2014. In Brazil, China and South Africa, the survey was fielded by phone; in Qatar and India, by interviews; and in the United States, online. To assess the burden of road traffic deaths and injuries on children worldwide, data from the Global Burden of Diseases Study was analysed.

Results More than 90 percent of parents in Brazil, China, India, Qatar and South Africa said more needs to be done to improve road safety for children. More than half of parents in five out of six countries said they are concerned about their child's safety on the way to school. In India, 66 percent of parents expect their child to be seriously hurt in a crash in the next year. In the United States, more than 70 percent of parents worry about their child being hit by a distracted or speeding driver on the way to school. Analysis of GBD data showed that, in 2010, road crashes were the leading cause of death among children ages 5 to 19 , with teenagers accounting for nearly half of deaths. More than 90 percent of road deaths among children occurred in low- and middle-income countries.

Conclusions Parents around the world are highly concerned about the safety of their children on the roads. These concerns are justified since road crashes are the leading cause of death for children ages 5 to 19. A strong focus on building awareness, expanding prevention programs, advocating for laws, and enhancing enforcement, consistent with the pillars of the UN Decade of Action on Road Safety, is needed. 